ONWARD

AND UPWARD

$\mathrm{C}$ hina's total number and global share of articles included in the Nature Index has increased since 2012. This upward trend corresponds with data from the larger Web of Science (WoS) database. The country's global share of articles, as well as those that are highly-cited, more than doubled between 2005 and 2015.

Over that decade, China increased its global share of articles in 14 fields tracked by the WoS.

The number of articles Chinese scientists published with international co-authors in top journals also increased each year since 2012. By 2016, international collaborations comprised more than $50 \%$ of the country's articles in the index.

While international papers make up a significant portion of China's high-quality research, this level of international co-authorship does not extend to all papers published in China. The country's share of articles with international coauthors indexed in the WoS remains below $25 \%$.

China's international collaboration rate remained stable between 2000 and 2012, sitting below $20 \%$, but it had increased to $24 \%$ in 2016 .

Yue Weiping, a data analyst with Clarivate Analytics, said the slower growth rate in papers from international collaborations was because China's overall research output had grown so dramatically.

A slower growth rate in international collaborations proportionate to China's overall increase could be attributed to language barriers and allocation of institutional resources, said Yue. For instance, China’s top universities have a higher rate of international collaboration than middle and bottom-ranked institutions. "Researchers in top universities have more opportunities or resources to collaborate with peers worldwide. Many researchers might seek international collaborations, but they don't have the resources."

Papers that result from international collaborations typically have more citations than domestic papers so it is understandable that high-impact journals such as those included in the index would comprise a large portion of papers from international collaborations, said Yue. Government policies to make Chinese research more global, including generous funding schemes to promote collaboration, will likely see its overall rate of international collaboration rise over the next decade.

DATA ANALYSIS BY LARISSA KOGLECK AND YUE WEIPING AND DAVID PENDLEBURY/ CLARIVATE ANALYTICS
HIGH-QUALITY

OUTPUT

China's number

of articles in

high-quality

journals included

in the Nature

Index has

increased unlike

those of the

United States

and Japan.

China
Japan
South Korea
United Kingdom
United States

GLOBAL SHARE

China has also

grown its share of articles in the

index, as the

United States

reduces its share.

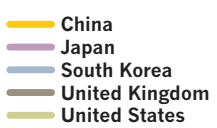

TOTAL OUTPUT

China's share of highly-cited papers has grown faster than its share of total articles indexed in the WoS.

China WoS articles (\%)

China highly cited papers (\% share)

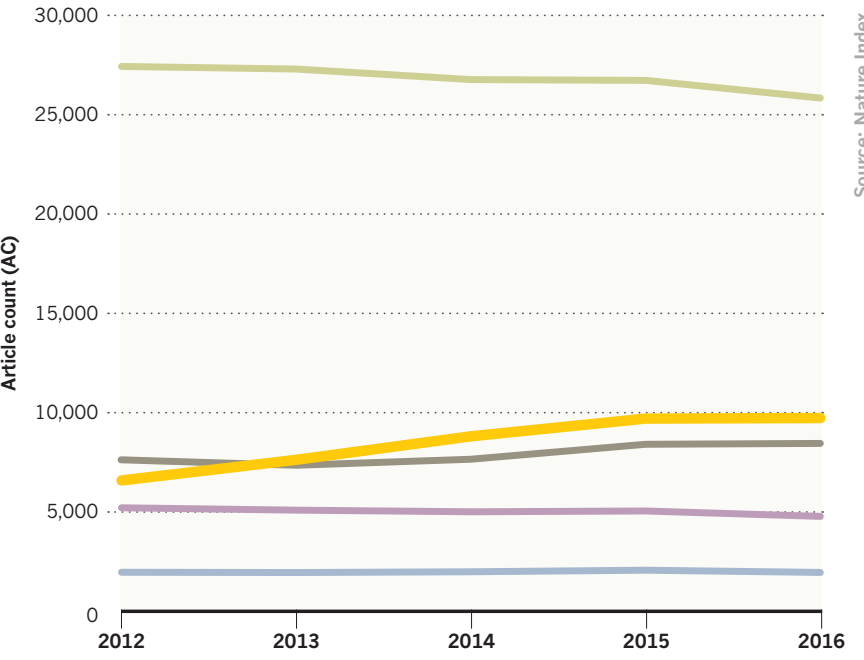

40

¿্ত

20
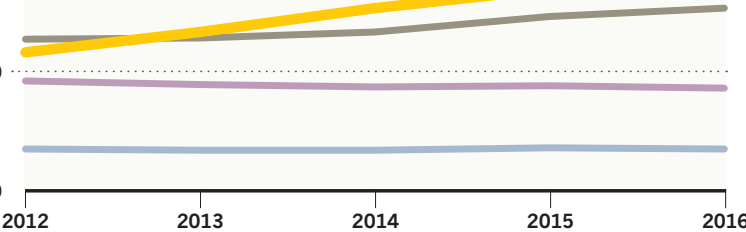
SUBJECT PERFORMANCE

China's global share of articles increased in 14 fields tracked by the WoS between 2005 and 2015.

2005 China's share of papers

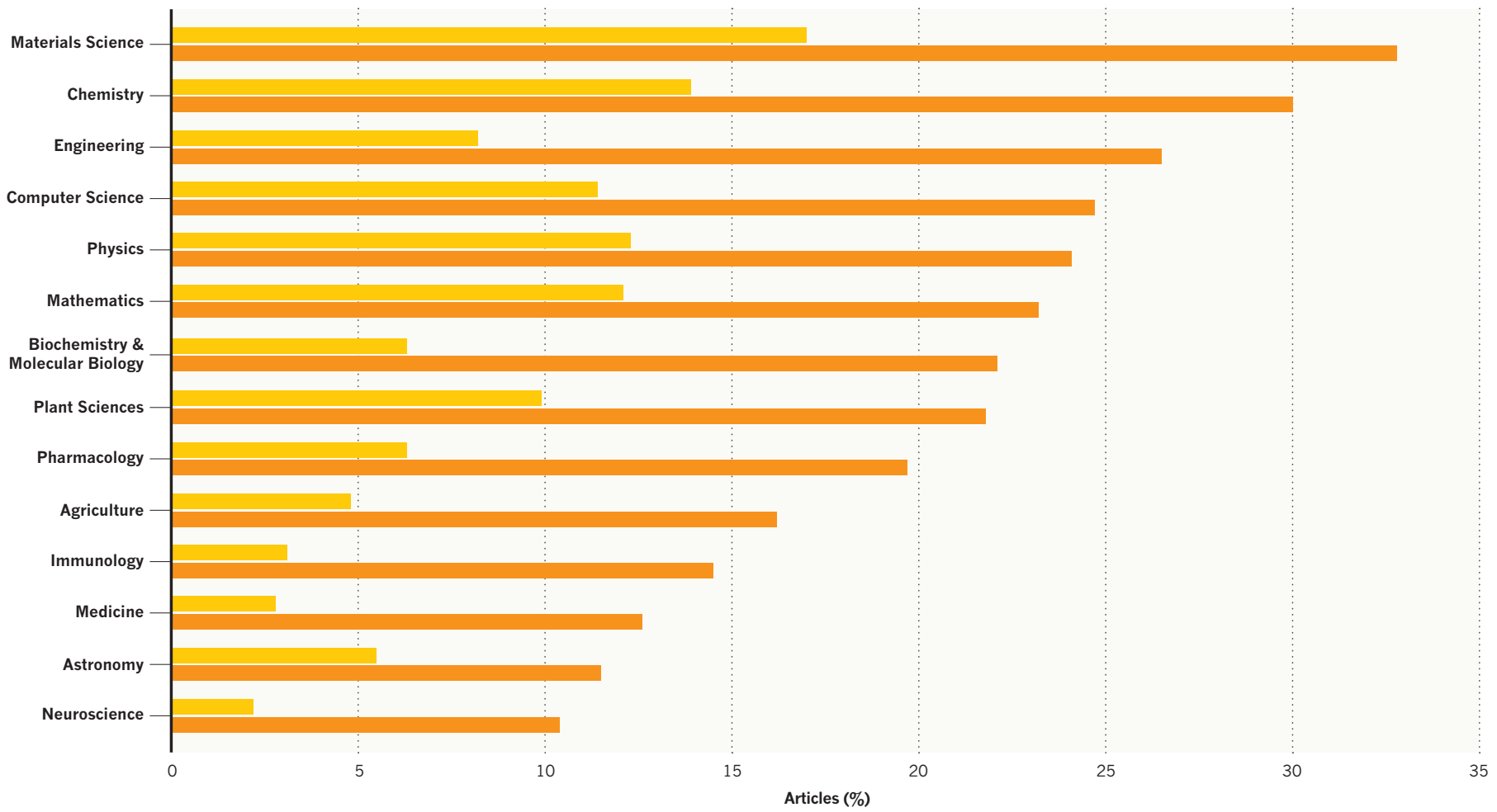

\section{HIGH-QUALITY COLLABORATIONS}

China's share of international papers in the index has Domestic increased since 2012 and surpassed domestic output in 2016.
TOTAL COLLABORATIONS

The percentage of Chinese papers with international coauthors in WoS has increased since 2010.
China

European Union Germany United Kingdom United States
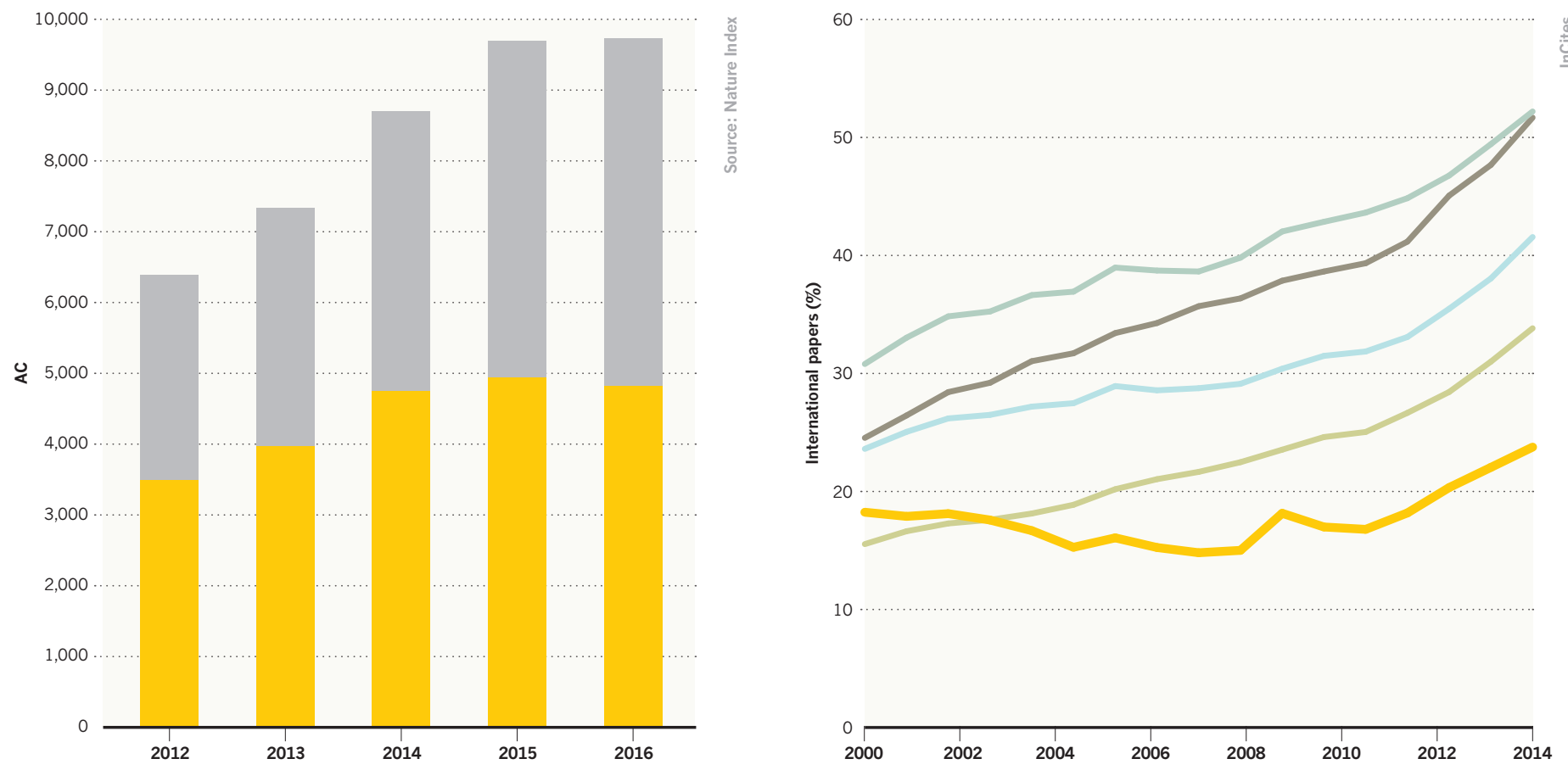

Excludes collaborations such as ATLAS with no affiliated HO in China. 